\title{
THE DETERMINATION OF AMMONIA IN SOIL.
}

\author{
BY DONALD J. MATTHEWS, \\ (Rothamsted Experimental Station.) \\ INTRODUCTORY.
}

IT was early recognised that the figures for the ammonia in soils determined by distillation at atmospheric pressure with strong alkalies were too high, owing to the simultaneous decomposition of nitrogenous compounds. Various methods were devised to overcome the difficulty.

Schloesing used a strong alkali but worked at air temperature. The material to be analysed was nixed with an alkaline solution in a shallow dish and placed close to another similar dish containing a dilute acid. A bell-jar was put over the two and the ammonia slowly diffused from the soil to the acid. The method was at best tedious and uncertain.

Schloesing also proposed another method, according to which the ammonia was extracted from the soil with hydrochloric acid. The filtered extract was boiled with a strong alkali to separate the ammonia. It was assumied that all the ammonia was extracted by the acid and that no more ammonia was formed during the operations. It is now known that neither assumption is justified.

Boussingault suggested the use of magnesia to liberate the ammonia, either at atmospheric pressure or in a partial vacuum.

In 1910 E. J. Russell ${ }^{1}$ investigated the subject more thoroughly and showed that even at low temperature and pressure nearly all the alkalies gave figures for ammonia which rose as the strength of the alkali w'as increased, and that there was therefore progressive decomposition of nitrogenous material. He found two exceptions. Magnesia did not give rise to much progressive decomposition because the low solubility made a strong solution impossible, and similar results were obtained with weak alcoholic potash. Russell accordingly suggested the use of these two methods as the best available at the time. Unfortunately when tested on soils to which a known amount of ammonia had been added they proved to be very inaccurate, the error varying from thirty to fifty per cent.

1 Journ. Agric. Sci., 3 (1910), p. 233. 
Before and since the date of Russell's paper many others have been published giving the results of comparative tests of the various processes in use. No reference need be made to them here, as the present paper deals with the aeration process only. An exception must be made however in the case of a paper by Baragiola ${ }^{1}$ and Schuppli, who used the magnesia.process in an apparatus essentially the same as that figured by Russell, and obtained a quantitative recovery of added ammonia. On the other hand they state that the majority of soils examined by them were free from ammonia, a result so unlike those obtained at Rothamsted and elsewhere as to throw some doubt on the reliability of their method.

In 1914 Potter and Snyder ${ }^{2}$ published an account of their experiments on the determination of amnionia in soil by the aeration method originally introduced by Folin for the analysis of physiological fluids. They made use of the apparatus recommended by $\mathrm{Kober}^{3}$ for the determination of relatively large amounts of nitrogen such as occur in the Kjeldahl process. Twenty-five grams of soil were aerated with 50 c.c. of water and 2 grams of sodium carbonate in a 500 c.c. Kjeldahl flask, and the ammonia was absorbed in dilute acid in a $16 \mathrm{oz}$. bottle. With an air current of about 250 litres an hour they obtained good results by aerating for 15 to 19 hours, and added ammonia was recovered nearly completely, the error being as a rule less than two per cent. and generally on the side of defect.

The only objection to the process is the length of time required, which not only makes it impossible to carry out more than one set of determinations in a day but also introduces serious risk of high results in the case of soils rich in unstable nitrogenous substances. One of the soils examined by the writer of the present paper showed measurable decomposition in six hours on aeration with magnesia and sodium chloride solution.

With the aeration apparatus described below it is possible to recover large quantities of added ammonia with an accuracy of 98 to 99.5 per cent. in six hours and with a nearly equal accuracy in three hours, while for most agricultural purposes an aeration of one and a half hours is sufficient.

1 Dr W. J. Baragiola and Dr O. Schuppli. "Die Bestimmung des Ammoniums im Boden u. s. w." Die Landwirtschaflichen Versuchs-Stationen. Band xc (191.7), p. 1.23.

2 Potter, R. S. and Snyder, R. S. "The Determination of Ammonia in Soils." Iowa Expl. Sta. Res. Bull., 17, October, 1914.

s Kober, P. A. and Graves, Sara S. "Quantitative Ammonia Distillation by Aeration for Kjeldahl, etc." III. Journ. Amet. Chem. Soc., 35 (1913), p. 1594. 


\section{APPARATUS.}

The apparatus is shown in Fig. 1, which is drawn to scale. The soil is put in the aerator, $A$, a strong glass tube $83 \mathrm{~cm}$. long and $23 \mathrm{~mm}$. in diameter with an egg-shaped bulb blown on it about $18 \mathrm{~cm}$. from the upper end. The air enters through the inlet tube, $B$, which has an internal diameter of from 3.5 to $4 \mathrm{~mm}$., and passes through the rubber stopper at the lower end of $A$ as close to the glass as possible. It is supported in a groove cut in the upper side of the cork block, $C$, which is cemented to

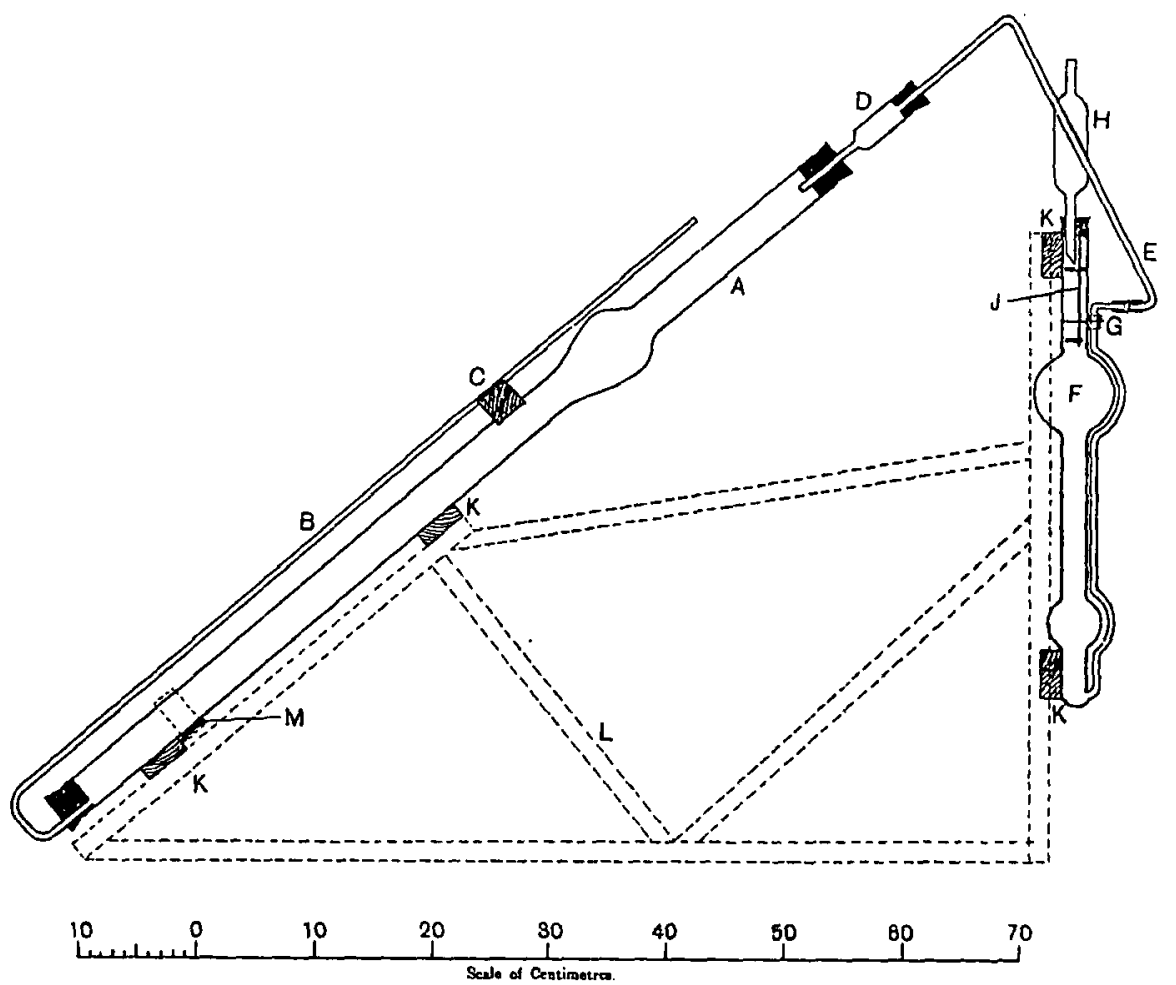

Fig. 1. One unit of the apparatus.

the aerator. Linen tape, not shown in the drawing, is bound firmly round the two tubes and the cork block. The inlet tube should fit in the groove loosely enough to allow of it and the stopper being withdrawn for one or two centimetres without unbinding the tape. The upper part of the inlet tube for 10 or 12 centimetres is bent to the right, upwards from the plane of the paper, at an angle of about $10^{\circ}$ to allow of connection to the next set of apparatus. The upper end of the aerator is 
closed by a rubber stopper carrying a funnel, $D$, which is loosely plugged with cotton wool to stop spiay. $D$ in its turn is connected with the absorber, $F$, by means of a rubber stopper and bent tube, $E$. If soft rubber stoppers are used there will be sufficient play to allow of the connections being made when both aerator and absorber are fixed in position. If any difficulty is experienced the tube $E$ may be cut and joined by rubber tubing.

The absorber $F$ is $40 \mathrm{~cm}$. high and has an internal diameter of 17 or $18 \mathrm{~mm}$. The capacity of the lawer bulb is about 50 c.c. and of the upper bulb about 120 c.c. At the upper end is a rubber stopper carrying a splash-bulb $H$, the lower end of which is ground off diagonally. A glass rod, $J$, fixed in the stopper carries two rubber discs the diameter of which is slightly less than that of the inside of the absorber; they are cut from the end of a rubber stopper and serve to stop splashing.

The side tube of the absorber is supported by slipping over it a short length of thick-walled rubber tubing, $G$, split lengthwise, and binding it to the absorber with soft copper wire.

It is important that there should be no space left between the rubber stoppers and the walls of the tubes. The stoppers should be chosen as nearly cylindrical as possible, of soft rubber, and should be cut off at the point where they cease to touch the glass.

The drawing shows only one set of apparatus, but six may be used, the air passing through each in turn. A suitable stand for six may be made by constructing two wooden frames of the shape and dimensions shown by the dotted lines, $L$, and joining them by four cross-bars, $K$, about $92 \mathrm{~cm}$. long. The aerators and absorbers are supported between blocks of cork glued and nailed to the four cross bars (these blocks are not shown in the drawing). They are held in position by tapes (also not shown) fastened to the back of the cross-bars by drawing pins. To prevent the aerators from slipping down, wedges of cork or wood, $M$, are fastened to them by rubber bands which may be cut from wide tubing.

An aerator and its absorber do not lie in the same plane, but as shown in the drawing, each absorber lies slightly neares the filter pump, that is, below the plane of the paper. It is then easy to connect the top of the splash bulb, $H$, with the inlet tube, $B$, of the next set of apparatus by a bent glass tube and rubber joints. The various joints should be made of the best soft rubber tubing wide enough to slip easily on to the glass. There is little danger of leakage as there is always reduced pressure inside.

The air entering the apparatus should be drawn from outside the laboratory and should be purified by passing through cotton wool, two 
washers filled with dilute sulphuric acid, and again through cotton wool or glass wool to stop acid spray. An air current of 300 litres per hour is suitable and may be obtained with one large filter pump worked by water, or two of the ordinary size working side by side and connected with a large glass bottle to equalise pressure. Good results have been obtained with currents as low as 200 litres and as high as 400 litres of air an hour. If the current is too small the soil is not properly broken up, while too strong a current may lead to loss of acid from the absorber by splashing.

The apparatus is used as follows. In each absorber is put rather more $N / 50$ sulphuric acid than it is expected will be required; if 25 grams of soil are taken, 1 c.c. of the acid is equivalent to 11.2 parts per million of ammoniacal nitrogen. A few drops of a 0.05 per cent. solution of methyl red in alcohol are added and then distilled water free from ammonia is poured in until the lower bulb is nearly full. The stoppers at the lower ond of each aerator are withdrawn sufficiently to allow of a small plug of cotton wool being fixed loosely in the end of the glass tube, and are then replaced. Twenty-five grams of the soil, previously passed through a $3 \mathrm{~mm}$. round-hole sieve, are weighed into each aerator; the cotton wool plugs prevent the inlet tube being blocked. Then 50 c.c. of the alkaline solution are added and about 1 c.c. of good paraffin lamp oil. The alkaline solution contains 108 grams of carbonate of soda crystals and 150 grams of sodium chloride per litre; it is best made up in large quantities and freed from ammonia as far as possible by passing a strong current of purified air through it for some hours. The blank should be carefully determined, and should not be more than equal to $0 \cdot 10$ c.c. of $N / 50$ acid in 50 c.c. In special cases, which are mentioned later, about 2 grams of recently ignited magnesia and 50 s.c. of a 25 per cent. solution of sodiuna chloride are used instead. The first absorber is connected to the air punip, a slow current of air is started, and the various connections are made one after another from the pump outwards. The soil may nove bodily up the aerator as a solid piug which however always breaks and flows back on reaching the bulb. As soon as this has happened the air current may be increased to full strength. In about five minutes the whole of the soil will be finely broken up. The acid in the absorber should fill the whole of the stem and the lower part of the buib with bubbles if absorption is to be complete1. If it does not rise high enough, more water should be used, or a loose glass rod capped at the bottom with rubber and bearing

1 The importance of ample scrubbing has been pointed out by B.S. Davisson, Journ. Indust. Eng. Chem., 10, 8 (Aug. 1918). 
two rubber discs similar to those fixed at the top of the absorber may be dropped into the tube, or finally a tube containing camphor may be inserted between the washers and the apparatus. This will cause the acid to break up into fine foam ${ }^{1}$; there is of course greater danger of losing acid by the carrying over of fine spray, so that particular attention should be paid to the rubber discs intended to stop this. After the aeration has been carried on for a sufficient length of time the air current is cut down as far as possible without actually stopping it and the connections are broken in turn beginning at the end farthest from the pump.

The titration is made with $N / 50$ sodium hydroxide and may be carried out in various ways. If the greatest accuracy is required it is best to proceed as follows. The upper stopper of the absorber is removed and the inside of the splash head and the glass rod and rubber discs are washed into a 200 c.c. flask of hard glass with a jet of water from a wash bottle. The bulk of the acid is then blown over into the flask through the side tube by applying the lips to the upper end of the absorber, but the latter is not washed out. Standard soda is then run into the flask until the colour of the indicator begins to change, when the liquid is poured back into the absorber and again blown back into the flask. The absorber is washed out twice with a little water. Owing to the absorber not having been washed out at first, the liquid will still be slightly acid. It is boiled for a few minutes to remove carbon dioxide, and the flask is closed with a rubber stopper carrying a guard tube filled with soda-lime and cooled under the tap. The titration is then completed.

If the greatest accuracy possible is not required, the following method may be adopted. A soda-lime guard tube is fitted to the wash bottle, and ancther to the top of the absorber so that no carbon dioxide enters it. The titration is carried out exactly as before, but the boiling is omitted. The results agree with those obtained by boiling to less than 0.10 c.c. of the acid, generally to 0.05 c.c. or less, and the saving of time is considerable. If this method is adopted the air should be passed through caustic soda before entering the sulphuric acid washers.

\section{EXPERIMENTAL.}

It is of course impossible to prove at present that any method for the determination of soil ammonia is absolutely correct. To do so it would be necessary to know every nitrogenous compound present in the soil and the extent to which it breaks down on aeration with an alkaline

1 I am indebted for this suggestion to Mr E. M. Crowther who has been using the apparatus for some months in this laboratory with complete success. 
substance, or else to find a soil free from ammonia and easily deconposable nitrogenous substances. In either case a known amount of ammonia could be added and the accuracy of the method checked by the completeness of the recovery. We certainly are far from knowing every nitrogenous compound in any soil, and it is very doubtful if there is any natural soil free from anmonia. It is true that Baragiola and Schuppli' ${ }^{1}$ state that the majority of soils examined by them by distillation in vacuo with nuagnesia were free from anmonia, but the writer has not yet found a soil which did not give up one or two parts of ammonia per million by the aeration method. Under the circumstances it is necessary to give a somewhat arbitrary definition to soil ammonia. Russell's ${ }^{2}$ definition is that "a substance is called an ammonium compound if it evolves ammonia rapidly, completely and in one stage when treated with weak alkalies at low temperatures."

For the purpose of the present paper it is not necessary to modify the definition beyond adding that the aeration process shall be used and that the weak alkali shall be magnesia in 25 per cent. sodium chloride. In nearly every case the sodium carbonate solution will give the same result as magnesia.

The definition is clearly defective. Formamide for instance is slowly decomposed under the conditions of the analysis, and would be included under the head of ammonia. It is probable however that for most agricultural purposes such easily decomposed substances may be considered as ammonia without any serious error.

Accepting the definition of ammonia, the accuracy of the method has to be proved.

In the first place it was found that if pure carefully dried ammonium sulphate was treated in the apparatus, the ammonia could be recovered almost quantitatively. In the last pair of experiments made $2.778 \mathrm{mg}$. of ammoniacal nitrogen was added and $2.780 \mathrm{mg}$. and $2.769 \mathrm{mg}$. were recovered. If this amount had been present in 25 grams of soil it would have corresponded to 111.1 parts per million, with a recovery of $111 \cdot 2$ and $110 \cdot 8$, the greatest error being $0 \cdot 3$ parts per million.

The process was next tested on a number of different soils, in as fresh a condition as possible, that is, the analysis was generally begun within two hours of the taking of the sample from the field. All soils were passed through a $3 \mathrm{~mm}$. sieve with round holes. The following were used:

1. Rothamsted soil, a rather heavy loam.

2. Rothamsted subsoil, a heavy clay.
1 Loc. cit.
2 Loc. cit. 
3. Woburn light sandy soil. This had been bottled off about eighteen hours before analysis.

4. Two heavily dunged tomato-house soils.

5. A calcareous soil taken from the outcrop of the chalk on the edge of the Rothamsted plateau.

In the first place experiments were made by aerating the soils for three, six, and nine hours to check the agreement of the results inter se and to determine the effect of varying the time.

Carefully measured amounts of ammonium sulphate solution were then added to soils in which the natural ammonia was determined simultaneously, and the total ammonia was determined to test the completeness of recovery. In order that this may be a strict test of the accuracy of the method it is necessary that the ammonia should be in equilibrium with the soil as regards adsorption. This condition is not easy to fulfil without introducing other sources of error. If the soil be wetted with a solution of ammonium sulphate and allowed to stand for some time, over night for instance, two changes may take place owing to bacterial action. More ammonia may be formed, and some may be lost by oxidation to nitrites and nitrates. The most probable result would be a rise in the ammonia and the recovery would appear to be more complete than it really is. The addition of antiseptics does not get over the difficulty entirely. If the mixture of chloride and carbonate of soda were added at the same time it would almost certainly stop all bacterial and enzyme action, but at the same time it would alter the adsorptive power of the soil and in some cases would cause slight decomposition. Even such an indifferent substance as toluene appears able to raise the ammonia content of a soil in a very short space of time, possibly because it does not inhibit enzyme action while it stops nitrification. The method adopted has been to add the ammonia about two hours before beginning the analysis; bacterial action would not cause any important change in this time, while equilibrium would be nearly reached. The difficulty is probably not so great as it might appear at first sight. Theory requires that adsorption should be instantaneous provided that mixing is also instantaneous. The curves show that less than one-fifth of the ammonia is evolved during the first six minutes when 110 parts per million are present. In this time the soil is thoroughly broken up and the remaining four-fifths are then in equilibrium. The conditions are the same as if we were dealing with a soil containing naturally about twenty per cent. less ammonia.

The rate of evolution of the ammonia was measured and some of the 
results are shown as curves in Fig. 2. In order to determine the rate, a small tap-funnel holding about 2 c.c. was sealed on to a vertical branch rising from the horizontal portion of the inlet tube of the absorber. A little acid, about one-tenth of the total amount which would be required, generally 1 c.c., was put in the absorber with the requisite quantity of indicator and water, and another similar quantity of acid in the funnel. A large Sugg's hourly-rate gas meter was attached outside the air-purifiers. The current was started and as soon as the indicator changed colour

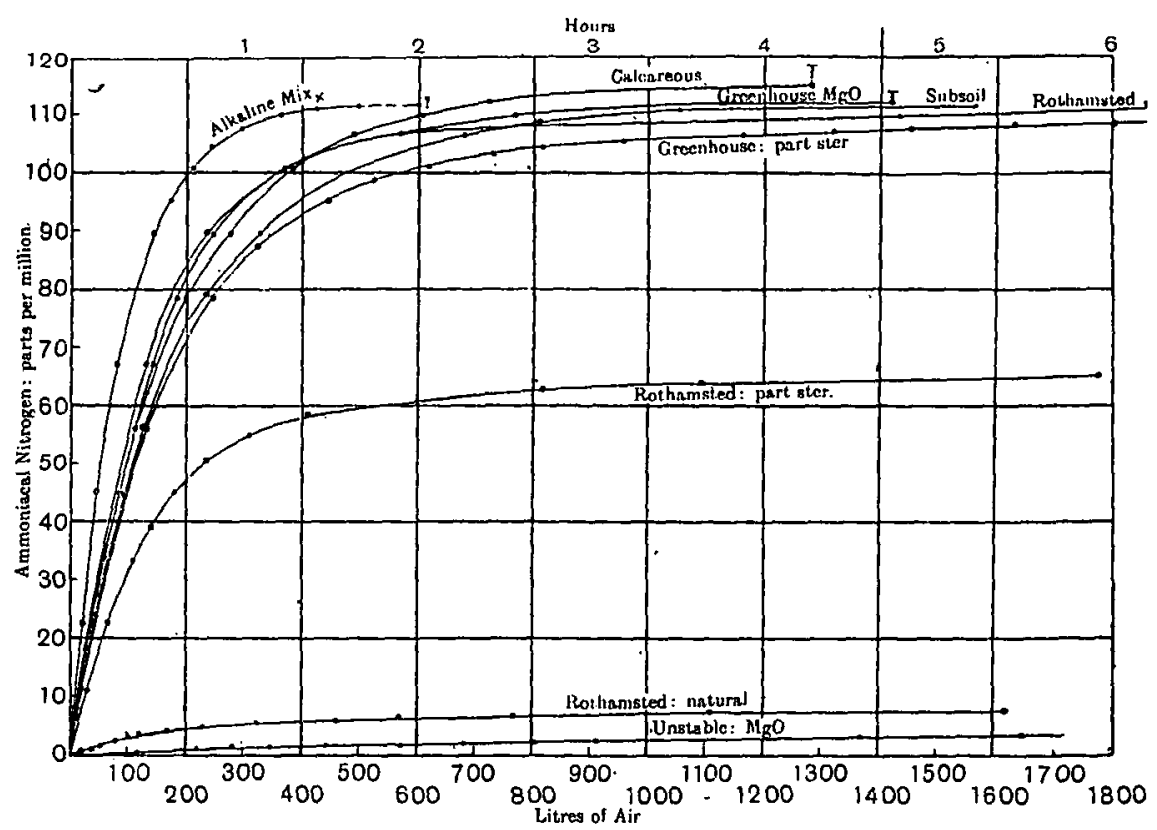

Fig. 2. Rate of evolutiun. Only a few of the points have been marked near the beginning. The short lines above the end of the curves marked "Calcareous" and "Greenhouse Mg0" show the sum of the original and added amounts.

the acid in the funnel was allowed to flow into the absorber and the meter was read. The operation was repeated as often as necessary with decreasing amounts of acid. Towards the end the indicator changed very slowly and the readings were somewhat uncertain. When ammonia had been added so that the total was high, $N / 50$ acid was used, but when only a few parts per million were present $N / 250$ acid was substituted.

The curves are if anything a more convincing proof of the accuracy of the process than the simple recovery of added ammonia. This is so particularly in those for soils in which ammonia had been developed 
slowly over a period of some weeks by partial sterilization, since in this case we may assume that equilibrium had been reached.

Rothamsted Soil. The soil was treated very easily in the apparatus; it broke up quickly and did not cake on the side of the tube. Duplicate analyses showed good agreement.

$\begin{array}{cccccccc}(1) & (2) & (3) & (4) & (5) & (6) & (7) & (8) \\ 1.4 & 1.8 & 2.6 & 6.4 & 7.3 & 5 \cdot 1 & 29.0 & 13.7 \\ 1.9 & 1.7 & 3.0 & 7.7 & 8.0 & 5.0 & 30.1 & 15 \cdot 6\end{array}$

The two last samples contained solid ammonium sulphate; they were taken on different days from a field which had been recently top-dressed. With the addition of known amounts of ammonia the results were as follows:

$\begin{array}{rccrcc}\text { Ammoniacal nitrogen in parts per million } \\ \text { No. } & \begin{array}{c}\text { Present } \\ \text { in soil }\end{array} & \text { Added } & \text { Total } & \text { Recovered } & \begin{array}{c}\text { Percentage } \\ \text { recovery }\end{array} \\ 9 & 3.3 & 55 \cdot 5 & 58.8 & 58.0 & 98.5 \\ 10 & 3.3 & 111 \cdot 1 & 114 \cdot 4 & 113.3 & 99.0 \\ 11 & 1.5 & 111 \cdot 1 & 112.6 & 110.9 & 98.5\end{array}$

The soils were aerated for from five to six hours. In Exp. 11 the ammonia and alkaline mix had been added to the soil and allowed to stand over night.

The lowest curve for a Rothamsted soil shows the rate of evolution of ammonia from a natural soil. The amount present, over 7 parts per million, is unusually high and is probably due to the soil having been taken to a depth of about 3 in. only from a stubble after some days of very hot weather. Such conditions would probably hinder nitrification more than ammonification. The increase of 0.4 parts per million between 1107 litres and 1619 litres is doubtful, so that a sufficiently correct result could have been reached in about three hours or a little more.

The curve marked "Rothamsted; part ster." shows the rate of evolution from soil in which the ammonia had been. slowly developing for some weeks as the result of the addition of about 60 parts per million in the form of an easily decomposable nitrogenous compound which would at the same time probably act as a partial sterilizer. The gradual increase of the ammonia in the soil had been watched by frequent analyses and the maximum was reached at the sample in question after which a slow fall set in. The curve is of interest because the ammonia would probably be in complete equilibrium with the soil. The aeration was carried on for three hours longer than the curve shows but no more ammonia could be detected with certainty, and 1000 litres of air gave 
results accurate enough for all practical purposes. There is no sign of progressive decomposition.

The upper of the three curves marked "Rothamsted" shows the evolution from soil to which ammonium sulphate had been added so as to bring the total up to 112.6 parts per million. Aeration was carried on up to 2360 litres of air but only 110.9 parts were recovered, an efficiency of 98.5 per cent. At 1000 litres of air about 108.5 parts had been collected, 2.4 parts less than at 2360 litres, that is ronghly only 2.4 parts passed over during the last 4.5 hours of the experiment.

Rothamsted subsoil. On account of its high clay content this soil might be expected to have considerable adsorptive powers. In three experiments in which ammonia had been added up to about 112 parts per million the recovery was $98 \cdot 0,98 \cdot 3$ and 98.6 per cent. The curve for one experiment is given in Fig. 2, and here again nearly all the ammonia was recovered with 1000 litres of air, aeration for 1.6 hours more producing only 0.7 p.p.m. of additional nitrogen.

Woburn light sandy soil. This had been in bottle in a damp condition for about eighteen hours before analysis. Ammonia was evolved very rapidly and its curve would lie nearer to that for "alkaline mix" than any of those drawn. It showed no signs of progressive decomposition; in one experiment 4.5 parts of nitrogen were evolved in six hours, and further aeration for three hours more produced a trace only, certainly less than half a part. In two experiments in which ammonia was added 98.5 and 98.8 per cent. of the total were recovered; in one of these 97.5 per cent. was recovered in three and a half hours.

Tomato-house soils. These had been used in the glass houses the previous year, receiving large quantities of stable manure, and at the end of the season had been thrown into heaps for use in pot experiments in partial sterilization. Owing to the size of the heaps and to their not having become airdried they may be considered fresh soils, but not in the sense in which the term can be applied to a soil taken directly from a field. They were somewhat more difficult to aerate properly as they clotted slightly on the sides of the tube just above the surface of the liquid.

One of the soils gave much the same results as those mentioned above. Direct determinations on the wet soil with the ordinary "alkaline mix" containing carbonate of soda gave the following results:

$\begin{array}{rrr}(1) & (2) & (3) \\ 2 \cdot 6 & 7 \cdot 5 & 3 \cdot 3 \\ 3 \cdot 3 & 9 \cdot 9 & 4.2 \\ 3 \cdot 4 & 10 \cdot 2 & 4.7\end{array}$


The differences for No. 2 are rather high. They may be due to defective sampling. The ammonia content points to rather active bacterial action, and the presence of large pieces of straw and such material made complete mixing very difficult.

The curve marked "Greenhouse; part. ster." refers to some of this soil which had been treated with a partial sterilizing agent free from nitrogen and allowed to stand for about two months in a large bottle. The ammonia was therefore in equilibrium with the soil. On aerating with 1000 litres of air 105.5 parts of nitrogen were found; at $1500,107.7$ parts, and at 1800 litres 108.6 parts. There appears to have been a slow evolution of ammonia from unstable nitrogenous material, but the error due to stopping at 1000 litres would not be great. In any case there does not appear at present to be any means of avoiding this slow decomposition.

A second glasshouse soil proved very unstable. On aerating with the "alkaline mix" it gave 3.9 parts in 3 hours, 5.4 parts in 6 hours, and 7.7 parts in 9 hours. Some of the soil which had been allowed to stand over night in the alkali and was then aerated for 9 hours gave 12.4 parts.

The soil was next aerated with magnesia and 25 per cent. sodium chloride solution. The results were better but progressive decomposition was still evident. The figures were at 3 hours 2.4 parts, at 6 hours 3.6 parts, and at 10 hours 5.4 parts; they are indicated in Fig. 2 by "Unstable: MgO."

Calcium carbonate was also used as the alkali. The results were independent of the time, but the recovery of added ammonia from a solution of ammonium sulphate was so poor, ten to fifteen per cent., that it was abandoned.

The curve marked "Greenhouse $\mathrm{MgO}$ " refers to this soil after the addition of about 110 parts of ammoniacal nitrogen. The recovery was 98 per cent. and there was little change after the first 1000 litres of air had passed.

With unstable soils such as this it is advisable to aerate with a definite amount of air, say 1000 litres, which can be easily determined by adding ammonia and drawing the evolution curve.

Calcareous soil. Soils high in chalk present greater difficulties than any of the for egoing, the recovery of added ammonia being less complete.

A soil taken in January at Basingstoke and high in moisture showed 3.2 and 3.0 parts of nitrogen on analysis. Ammonium sulphate was added to bring it up to 55 parts per million but only 90 per cent. could be recovered. Two other experiments failed to recover more than 86 and 88 per cent. The analyses were then repeated near a steam-heated 
radiator, and very unexpectedly the recovery fell to less than 70 per cent. The soil was now no longer fresh enough to make it worth while carrying the experiments further.

Later the experiments were repeated on a soil containing 28 per cent. of chalk from an outcrop on the edge of the Rothamsted plateau. The sample was very dry and full of small fragments of roots and such material. Added ammonia was recovered to the extent of about 95 per cent. only.

A fresh sample of the same soil was analysed after passing through a $3 \mathrm{~mm}$. round hole sieve and found to contain 3 parts per million of nitrogen. Ammonia solution was added to another portion to bring the nitrogen up to 110 parts, and 94 per cent. only was recovered. A third portion was finely ground before analysis, and from this 99 per cent. of nitrogen could be recovered. Lumps of chalk picked out and crushed also gave up 99 per cent. of added nitrogen without difficulty.

A fourth sample freshly taken gave 3.9 parts on soil passing the $3 \mathrm{~mm}$. sieve and $5 \cdot 5$ parts on a finely ground portion. The analyses were repeated next day with the same result. Added ammonia was recovered to the extent of 96 per cent. from the coarse soil and 97 per cent. from the fine soil. The evolution curve for the latter is given in Fig. 2. It will be seen that the shape is similar to that of the others.

The addition of potassium oxalate did not increase the recovery. Many other experiments have been made on this soil which need not be described here as they do not throw any light on the problem. At present one can only say that on a finely ground soil the accuracy is fair. In summer fine grinding presents no difficulty, but with a wet soil it would be almost impossible.

Further experiments will be made with calcareous soils.

The effect of substituting magnesia with or without sodium chloride for the "alkaline mix" has also been studied. It was found that a soil allowed to stand over night with magnesia and water showed a considerable rise in ammonia. This may be attributed to bacterial action, the conditions being nearly an optimum. There is a chance of this taking place even during aeration so that the use of magnesia alone cannot be recommended.

Magnesia with strong sodium chloride, from 15 to 25 per cent. solution, also gave higher figures for ammonia on field soils than did "alkaline mix," but the difference was generally not more than one or two parts. It is possible that while bacterial action was stopped by the sodium chloride, enzyme action was not inhibited. 
Magnesia however has one serious disadvantage in that it makes the soil clot on the sides of the tubes so that it is not properly aerated. It is better to use the "alkaline mix" except for very unstable soils such as the glasshouse soil mentioned above.

The shape of the curves is evidently connected with the adsorptive power of the soils. This point is still being investigated and will form the subject of another paper.

\section{SUMMARY.}

Ammonia can be recovered from soil with an efficiency of 98.5 to 99.5 per cent. in six hours in the apparatus described.

For most purposes it is sufficient to aerate the soil for three hours.

Highly dunged glasshouse soils undergo partial decomposition in the cold with magnesia. In such cases the soil should be aerated with magnesia and strong sodium chloride solution for a definite time, say three hours.

The complete recovery of added ammonia from a calcareous soil is difficult unless the soil is finely ground.

(Received 30th August 1919.) 